\title{
POR UMA PROPOSTA PARA A DIDATIZAÇÃO DE GÊNEROS NO ENSINO FUNDAMENTALL ${ }^{15}$
}

\author{
Sílvio Ribeiro da Silva (UFG) \\ ssilva@uol.com.br e ssilva@jatainet.com.br
}

\section{Considerações iniciais}

Apresentar uma proposta de trabalho com os gêneros na escola pode não ser tarefa fácil, uma vez que parece não existir muita clareza quanto a isso nem mesmo nos Parâmetros Curriculares Nacionais de Língua Portuguesa (PCN). No entanto, o que apresento neste pequeno ensaio é o que acredito ser essa proposta, com um trabalho que seria desenvolvido do $6^{\circ}$ ao $9^{\circ}$ anos do Ensino Fundamental. Espero poder, com isso, incendiar um pouco mais as discussões já existentes sobre o assunto.

\section{Didatizando gêneros}

Primeiramente, penso ser necessário o professor de língua materna encarar a língua e a linguagem como práticas sociais e lugar de interação entre sujeitos sociais. Faz-se necessário que a sala de aula seja considerada um espaço de produção de linguagem. Ela deve ser vista como o lugar onde atividades interlocutivas são construídas por sujeitos (alunos e seus respectivos professores e alunos/alunos). Também é preciso que a linguagem seja entendida como interação, saindo do universo tão amplamente divulgado pela escola de que ela é um simples código estático. É necessário que a língua seja vista enquanto forma de ação social e histórica. O que é comum percebermos é uma visão de língua que não a vê como totalidade. Da mesma forma, o texto não é visto enquanto parâmetro da realização linguística. Em segundo lugar, seria preciso que se tivesse certa orientação teórica a respeito do gênero.

\footnotetext{
${ }^{15}$ Este trabalho contribui com as investigações referentes às práticas de reflexão sobre a língua desenvolvidas pelos integrantes dos grupos Grupo de Estudos da Linguagem: análise, descrição e ensino (UFG/CNPq) e Livro Didático de Língua Portuguesa Produção, Perfil e Circulação (UNICAMP/IEL/CNPq).
} 
Sabe-se que a palavra gênero sempre foi bastante utilizada pela Retórica e pela Literatura com um sentido especificamente literário, identificando os gêneros clássicos - lírico, épico, dramático - e os gêneros modernos, como novela, drama, conto etc. Mikhail Bakhtin - pesquisador russo que, no início do século XX, dedicou-se aos estudos da linguagem e da literatura - foi o primeiro a empregar a palavra gênero com um sentido mais amplo (CADORE, 1996) ${ }^{16}$.

Para Bakhtin (1974), todos os textos que produzimos, orais ou escritos, trazem em si um conjunto de características relativamente estáveis, por mais que não tenhamos consciência delas. Essas características dão forma a um variado conjunto de gêneros, cuja caracterização pode ser feita por três aspectos básicos coexistentes: o tema, a estrutura e o estilo (procedimentos recorrentes de linguagem). Para Bakhtin (1974), os gêneros podem ser divididos em dois grandes grupos: gêneros primários e gêneros secundários. Os primários, em geral mais espontâneos, costumam ser produzidos nas situações corriqueiras de comunicação, predominantemente orais, mas não somente. Os secundários exigem uma ação discursiva específica, por se apresentarem mais presos a certas situações discursivas formais. Apresentam predomínio da escrita, mas não somente.

As diferentes linhas de pesquisa linguística de orientação bakhtiniana têm demonstrado que a atuação do professor de língua portuguesa no ensino fundamental, quando feita pela perspectiva dos gêneros, não só amplia, diversifica e enriquece a capacidade do aluno de produzir textos orais e escritos, mas também aprimora sua capacidade de recepção, isto é, de leitura/audição, compreensão e interpretação de textos (ANTUNES, 2002). Além disso, conscientiza o aluno das funções sociais dos diferentes tipos de texto e seus usos em sua comunidade discursiva (HYON, 1994, apud MOTTA-ROTH, 2000).

O ensino de produção de texto, feito por essa perspectiva, continua a abordar os tipos textuais ${ }^{17}$ tradicionalmente trabalhados

\footnotetext{
${ }^{16}$ Em minha tese de doutorado, defendida em 2008 no Programa de Pós-Graduação em Linguística Aplicada da UNICAMP, apresento ampla discussão sobre a origem dos estudos sobre gênero no mundo.

${ }^{17}$ Segundo Marcuschi (2002a, p. 20), o termo tipo textual é usado para designar uma espécie de sequência teoricamente definida pela natureza linguística de sua composi-
} 
em cursos de redação - a narração, a descrição e a dissertação, incorporando-os numa perspectiva mais ampla, de variedade de gêneros. Defendo a ideia de que o trabalho apenas com os tipos textuais não é totalmente eficiente, vez que oferece problemas para o ensino, tendo em vista que não é possível ensinar narrativa em geral, porque, embora possamos classificar vários textos como sendo narrativos, eles se concretizam em formas diferentes - gêneros - que possuem diferenças específicas (BARBOSA, 2000, p. 156). Isso justifica o porquê da prioridade pelo ensino do gênero, não pelo tipo textual, embora todo gênero realize necessariamente uma ou mais sequências tipológicas e todos os tipos inserem-se em algum gênero.

Até recentemente, o ensino de produção de textos (muito mais voltado para a perspectiva da redação) era feito como um procedimento único e global, como se todos os textos fossem iguais e não apresentassem determinadas dificuldades e, por isso, não exigissem aprendizagens específicas. A metodologia de ensino de escrita, presente nessa prática - a qual consiste no trabalho com a trilogia narração, descrição e dissertação -, tem seus fundamentos baseados uma concepção voltada substancialmente para a obtenção de dois objetivos: a formação de escritores literários (caso o aluno se aprimore nas duas primeiras modalidades textuais) ou a formação de cientistas (caso da terceira modalidade) (ANTUNES, 2002). Além disso, essa concepção guarda em si uma visão equivocada de que narrar e descrever seriam ações mais "fáceis" do que dissertar, ou mais adequadas à faixa etária, razão pela qual esta última tenha sido reservada às séries finais - tanto no ensino fundamental quanto no ensino médio.

Meurer (apud MOTTA-ROTH, 2000, p. 169) argumenta em favor de uma visão do ensino de línguas que se baseie no desenvolvimento da competência de uso de um número crescente de gêneros em termos do desenvolvimento de uma compreensão das práticas discursivas e das relações sociais associadas aos usos de diferentes gêneros. $\mathrm{O}$ ensino de produção de texto pela perspectiva dos gêneros garante um resultado mais satisfatório, já que põe o aluno, desde sempre, em convívio com uma verdadeira diversidade textual, com

ção (aspectos lexicais, sintáticos, tempos verbais, relações lógicas). Os tipos textuais são limitados e o autor os classifica em narração, argumentação, exposição, descrição injunção. 
os diferentes gêneros em uso social. Além disso, a aprendizagem deve ser em espiral ${ }^{18}$. Os gêneros devem passar por um processo de progressão, conforme sugerem Dolz e Schneuwly (2004).

Acredito que, no Ensino Fundamental, dentre outros, os gêneros que podem ser trabalhados são os seguintes ${ }^{19}$ : o bilhete, a carta, o telegrama, o conto, a lenda, a fábula, a crônica, o poema, a receita, o editorial, a carta argumentativa, a carta do leitor, o texto argumentativo, a entrevista, o texto publicitário, o editorial, a bula, o texto de opinião, o texto científico, o diário, os gêneros virtuais, da esfera digital.

Ao falar em gêneros virtuais, da esfera digital, não podemos deixar de considerar o trabalho na escola com o gênero mídia virtual (MARCUSCHI, 2002b), especialmente se levarmos em conta que, atualmente, até mesmo os jovens oriundos de famílias de baixa renda já podem ter acesso ao mundo virtual, frequentando lan houses, onde, por um preço acessível a quase todos, eles podem ler e enviar emails e "frequentar" salas de bate papo, participar de redes sociais, além de jogar e executar outras tarefas.

Concordo com Marcuschi, que não categoriza as home pages como gênero, da mesma forma que não o faz com os jogos interativos, uma vez que os primeiros não passam de um catálogo ou uma vitrine pessoal ou institucional, sendo mais bem categorizados como suporte, o mesmo acontecendo com os segundos.

Marcuschi (2002b) diz desconhecer quantos gêneros poderiam ser identificados na mídia virtual. Entre os gêneros mais conhecidos, o autor apresenta os seguintes: 1- e-mail: correio eletrônico na forma com formas de produção típicas; 2- bate-papo virtual em aberto: inúmeras pessoas interagindo simultaneamente; 3- bate-papo

\footnotetext{
${ }^{18}$ Segundo Dolz e Scheuwly (2004, p. 64), uma proposta de trabalho em espiral é relevante porque objetivos semelhantes são abordados em níveis de complexidade cada vez maior ao longo da escolaridade. Além disso, um mesmo gênero pode ser abordado diversas vezes ao longo da escolaridade, com graus crescentes de aprofundamento.

${ }^{19}$ Marcuschi (2002b) diz que não acredita haver gêneros ideais para o ensino de língua. Concordo com ele. Inclusive quando diz que é provável que se possam identificar gêneros com dificuldades progressivas, do nível menos formal ao mais formal, do mais privado ao mais público e assim por diante.
} 
virtual reservado: variante do item anterior, mas com as falas acessíveis apenas aos dois selecionados, embora vendo todos os demais em aberto; 4- bate-papo agendado (MSN): variante do item anterior, mas com a característica de poder ter sido agendado e oferecer a possibilidade de mais recursos tecnológicos na recepção e envio de arquivos, como, por exemplo, o fato de o receptor ter a possibilidade de ver, ao vivo, a imagem do interlocutor; 5- bate-papo virtual em salas privadas: sala privada com apenas os dois parceiros de diálogo presentes, uma espécie de variação dos bate-papos de tipo 2; 6- entrevista com convidado: forma de diálogo com perguntas e respostas num esquema diferente dos anteriores; 7- aula virtual: interações com número limitado de alunos tanto no formato de $e$-mail ou de arquivos hipertextuais com tema definido em contatos geralmente assíncronos; 8- bate-papo educacional: interações síncronas no estilo dos chats com finalidade educacional, geralmente para tirar dúvidas, dar atendimento pessoal ou em grupo e com temas prévios; 9- videoconferência interativa: realizada por computador e similar a uma interação face a face, usa a voz pela rede de telefonia a cabo; 10- lista de discussão: grupo de pessoas com interesses específicos, que se comunicam em geral de forma assíncrona, mediada por um responsável que organiza as mensagens e, eventualmente, faz triagens; 11endereço eletrônico: o endereço eletrônico, seja o pessoal para $e$ mail, seja para home-page, tem hoje características típicas, e é um gênero (MARCUSCHI, 2002b, p. 11).

Sobre os gêneros virtuais que ainda não foram incluídos no trabalho escolar, convém dizer, concordando com Schneuwly e Dolz (2004, p. 80), que a introdução de um gênero na escola é o resultado de uma decisão didática que visa objetivos precisos de aprendizagem que são de dois tipos: a) trata-se de aprender a dominar o gênero, primeiramente, para melhor conhecê-lo ou apreciá-lo, para melhor saber compreendê-lo, para melhor produzi-lo na escola ou fora dela e, b) em segundo lugar, para desenvolver capacidades que ultrapassam o gênero e que são transferíveis para outros gêneros próximos ou distantes. Isso tem ocorrido com os gêneros da esfera virtual desde que foram incluídos na escola.

Convém ressaltar que, segundo Koch (2002), a escolha do gênero se dá em função dos parâmetros da situação que guiam a ação. Além disso, como afirmam Schneuwly e Dolz (2004), a adapta- 
ção da escolha dos gêneros deve ser feita de acordo com a situação de comunicação, com as capacidades de linguagem apresentadas pelos alunos. Os autores dizem, ainda, que é a situação de comunicação a geradora, quase automática, do gênero, e este não é descrito, sequer ensinado, mas aprendido pela prática de linguagem escolar, através das definições próprias à situação e das interações; o gênero nasce da situação.

Por que sugerir o trabalho com os gêneros anteriormente aqui elencados e não com outros? É preciso que se trabalhe com gêneros que sejam fundamentais para a composição de textos que se concretizem nesses e noutros gêneros. A utilização que o aluno fará desses gêneros pela vida afora reforça a escolha pelos aqui colocados. Schneuwly e Dolz (2004) defendem a ideia de que, na escola, devem ser reproduzidas situações de práticas de linguagem cujo objetivo será fazer com que o aluno domine, o mais perfeito possível, o gênero correspondente à prática de linguagem para que, instrumentado, possa responder às exigências comunicativas com as quais será confrontado.

Ao final do Ensino Fundamental, o aluno teria convivido com pelo menos, vinte gêneros e com a possibilidade de ter visto uma média de cinco por série, os quais teriam sido estudados, analisados e produzidos a partir de orientações sistemáticas. Seria possível a elaboração e o desenvolvimento de uma espécie de grade programática de gêneros. À medida que os anos escolares fossem passando, o aluno iria percebendo a necessidade de uma sistematização melhor com os gêneros já estudados, e a necessidade de conhecimento de novos gêneros, conforme fosse a solicitação de sua atuação social.

Deve-se ter consciência de que a transferência de um gênero para a escola, como a bula, por exemplo, implica em transformação, já que ele sofreu uma mudança de lugar social, diferente da sua origem. Nessa mudança, o gênero não tem mais o mesmo sentido (SCHNEUWLY; DOLZ, 2004). Não se pode esquecer de que alguns desses gêneros podem ocorrer tanto na modalidade oral quanto na escrita (a entrevista ou o texto publicitário, por exemplo). Nesse caso, o interessante é o desenvolvimento de um trabalho com as duas modalidades, mostrando aos alunos as especificidades de cada um nessas modalidades. 
O ensino-aprendizagem de produção de texto pela perspectiva dos gêneros direciona o papel do professor de língua materna atual para outro caminho. Atualmente, ele deixou de ser visto como um especialista em textos literários ou científicos, distantes da realidade e da prática textual do aluno, passando a ser visto como um especialista em diferentes modalidades textuais, orais e escritas, necessárias para a vivência social. Dessa forma, a sala de aula tornase uma oficina de textos de ação social, cuja concretização se dá a partir da realização de alguns projetos de trabalho e da adoção de certas estratégias didáticas.

$\mathrm{O}$ ato de escrever na escola deve ser democratizado: todos os alunos do ensino fundamental devem aprender a produzir variados gêneros. É possível que um aluno, ao se apropriar dos procedimentos que envolvem a produção de um texto narrativo, não apresente tanta habilidade quanto outro aluno, mas ele poderá dar indícios de que argumenta com propriedade em textos argumentativos orais (debates) ou escritos.

Penso que o trabalho com os gêneros no ensino fundamental não deve ser limitado apenas ao ato de ler e escrever textos em gêneros diferentes. Aos alunos poderia ser proposta, ainda, a atividade de identificação dos gêneros. Defendo essa atividade com base em Marcuschi (2002a), quem diz que é importante levar os alunos a analisar eventos linguísticos e a identificar as características de gênero de cada um. É um exercício instrutivo e que também permite praticar a produção textual. O autor afirma (p. 35) que seria muito interessante e produtivo pôr na mão do aluno um jornal diário ou uma revista semanal e propor a seguinte tarefa: identifique os gêneros textuais aqui presentes e diga quais são as suas características centrais em termos de conteúdo, composição, estilo, nível linguístico e propósitos. Conforme diz ele, essa atividade, por mais modesta que seja a análise feita pelos alunos, será sempre muito promissora.

A atividade de identificação do gênero serviria para que o aluno percebesse que os textos funcionam dentro de um determinado grupo, refletindo um comportamento social (ANTUNES, 1996, p. 366).

Ao aluno seriam solicitadas as seguintes tarefas após a leitura de textos: a comparação entre eles, o seu agrupamento por uma relação de semelhança e a apresentação de justificativas que explicitas- 
sem as razões que levaram a tal agrupamento. Poderiam ser feitas ao aluno as seguintes perguntas: com relação aos textos apresentados, quais são diferentes? Se diferentes, o que diferencia um do outro? Como você designaria esses textos? Por quê? A orientação básica que deveria ser dada é que o aluno deveria agrupar os textos a partir do modo como eles dizem as coisas, a partir do seu funcionamento textual e discursivo.

Com essa atividade, provavelmente, ele estaria indo além da simples categorização dos textos quanto ao gênero, uma vez que deveria observar questões relacionadas a quem produz, quem distribui e quem consome variados textos, quais suas intenções implícitas e explícitas e como e por que os textos adquirem coerência.

Ao falar dessa tarefa de identificação de gêneros, busco apoio em Swales (1984, p. 04), quem diz que a análise de gênero ajuda os estudantes a tornarem-se leitores mais críticos e mais perceptivos de seu próprio texto. Se os alunos são conscientes de como um gênero é organizado, tal conhecimento poderá ajudá-los a produzir textos de boa qualidade e capacitá-los a direcionar a sua própria leitura de uma melhor forma (KUSEL, 1992, p. 460). Para Kusel, se o professor orientar os alunos com relação à organização textual, estes desenvolverão expectativas sobre a forma de estruturar o texto, contribuindo para uma melhor percepção da sua coerência (ARAÚJO, 1996).

Levando em consideração que os textos que circulam na sociedade se manifestam sempre em um ou outro gênero, um maior conhecimento do funcionamento desses gêneros é importante, tanto para a produção quanto para a compreensão de textos.

Convém ressaltar que as considerações que faço aqui deveriam ser observadas pelo professor de língua materna, levando em conta o fato de que, em quaisquer circunstâncias vividas pelo Homem, o uso da linguagem sempre visa à interlocução e ao preenchimento de uma necessidade comunicativa. Tendo em vista essa necessidade, um trabalho com língua materna, baseado nos gêneros, traria ao aluno não apenas o cumprimento de um ritual escolar, feito a partir da orientação do autor do livro, ou do professor, muitas das vezes produzindo textos que não teriam valor efetivo na sua vida social. Ao contrário disso, ele faria textos que seriam instrumentos de interlocu- 
ção dele com os outros. Se o professor faz com que o aluno tenha consciência de como um gênero é organizado, este poderá usar esse conhecimento para produzir textos de boa qualidade e ainda será capaz de direcionar a sua própria leitura de uma melhor forma (KUSEL, 1992).

O trabalho com gêneros pressupõe a hipótese de que eles são instrumentos para agir em situações de linguagem. Dolz e Schneuwly (2004) dizem que

O trabalho escolar faz-se sobre os gêneros quer se queira ou não. Eles constituem o instrumento de mediação de toda estratégia de ensino e o material de trabalho, necessário e inesgotável, para o ensino da textualidade. A análise de suas características fornece uma primeira base de modelização instrumental para organizar as atividades de ensino que estes objetos de aprendizagem requerem. (DOLZ; SCHNEUWLY, 2004, p. 51)

$\mathrm{Na}$ escola, especificamente com o $6^{\circ}$ até o $9^{\circ}$ ano, o trabalho com os gêneros é uma ferramenta didática interessante, na medida em que o aluno já traz consigo certo conhecimento sobre gênero, uma vez que faz uso dele no seu cotidiano fora da escola. Intuitivamente, as pessoas sabem que os textos se desenvolvem em sequências não aleatórias ${ }^{20}$. Qualquer texto traz consigo indicadores de suas especificidades de gênero. Como as pessoas conseguem, naturalmente, pelo menos grande parte delas, identificar o gênero ao qual o texto pertence, poderíamos afirmar que a capacidade de identificação dos gêneros faz parte do conhecimento cultural das pessoas, é parte de seu conhecimento de mundo, de seu letramento.

Uma estratégia didática que pode trazer bons resultados é aproveitar as experiências vividas pelo aluno com os gêneros cotidianos e a metalinguagem naturalmente adquirida nas experiências de leitura e produção escrita.

\section{Considerações finais}

\footnotetext{
${ }^{20}$ Adam desenvolve a noção de sequências textuais tendo por base a hipótese de existência de unidades mínimas de composição textual, ou seja, protótipos, que, agrupados, constituem o produto final. (ALVES-FILHO; SILVA, 2010)
} 
Ao longo dos anos de escolaridade, o aluno deveria ampliar o contato e a capacidade de uso de um maior número possível de gêneros, desde os mais simples até os mais complexos, os quais exigem maiores capacidades para sua construção e consumo, cabendo à escola essa tarefa. $\mathrm{O}$ trabalho com variados gêneros daria ao aluno a oportunidade de se capacitar para uma atuação comunicativa melhor em alguns tipos de situação e não em outros.

Uma proposta de ensino de língua que prioriza o trabalho com os gêneros traz aos textos uma dimensão concreta. Além disso, as regras linguísticas (gramaticais) deixam de ser apenas artefatos integrantes de um texto, passando a apresentar um caráter funcional, sendo percebidas como particularidades pertencentes a cada gênero ${ }^{21}$.

Fazendo isso, certamente a escola estaria dando ao aluno a oportunidade de se apropriar devidamente de diferentes gêneros socialmente utilizados, sabendo movimentar-se no dia a dia da interação humana, percebendo que o exercício da linguagem será o lugar da sua constituição como sujeito (SILVA, 2010). A atividade com a língua, assim, favoreceria o exercício da interação humana, da participação social dentro de uma sociedade letrada.

\section{REFERÊNCIAS BIBLIOGRÁFICAS}

ALVES-FILHO, S. C.; SILVA, S. R. da. Algumas contribuições de Bakhtin, Schneuwly e Adam para os estudos sobre gêneros. Soletras. Ano X, No 20, jul./dez.2010 - Suplemento. São Gonçalo: UERJ, 2010, p. 17-28.

ANTUNES, I. C. A abordagem da textualidade através da tipificidade dos gêneros textuais. Boletim da ABRALIN, 21, p. 363-378, 1996.

. Língua, gêneros textuais e ensino: considerações... Perspectiva. Florianópolis, Vol. 20, nº 01, 2002, p. 65-76.

\footnotetext{
${ }^{21}$ Em Silva e Lima (1999), fazemos uma análise do funcionamento textual-discursivo de conectivos nos gêneros textuais bula de remédio, notícia policial de jornal escrito, propaganda publicitária de carro (veiculadas pela revista Veja). Levamos em consideração que os conectivos apresentam funcionamento textual-discursivo variado em diferentes gêneros textuais.
} 
ARAÚJO, A. D. Lexical signalling: a study of unspecific nouns in book reviews. Florianópolis: UFSC, 1996. Tese de Doutorado.

BAKHTIN, M. (1952-53). Os gêneros do discurso. In: Estética da criação verbal. São Paulo: Martins Fontes, 1979, p. 277-326.

BARBOSA, J. Do professor suposto pelos PCNs ao professor real de língua portuguesa: são os PCNs praticáveis?. In: ROJO, R. (org.). A prática de linguagem em sala de aula: praticando os PCNs. Campinas: Mercado de Letras, 2000.

CADORE, L. A. Curso prático de português. São Paulo: Ática, 1996.

DOLZ, J.; SCHNEUWLY, B. Gêneros e progressão em expressão oral e escrita: elementos para reflexões sobre uma experiência suíça (francófona). In: SCHNEUWLY, B., DOLZ, J. et al. Gêneros orais e escritos na escola. Campinas: Mercado de Letras, 2004, p. 41-70.

KUSEL, P. A. Rhetorical approaches to the study and composition of academic essays. System, 20(4), p. 457-469, 1992.

MARCUSCHI, L. A. Gêneros textuais emergentes e atividades linguísticas no contexto da tecnologia digital. Trabalho apresentado no congresso do GEL (Grupo de Estudos Linguísticos do Estado de São Paulo) - USP, 2002a, (mimeo).

. Gêneros textuais: definição e funcionalidade. In: DIONÍSIO, Ângela et al. Gêneros textuais e ensino. Rio de Janeiro: Lucerna, 2002b.

KOCH, I. G. V. Os gêneros do discurso. In: _. Desvendando os segredos do texto. São Paulo: Cortez, 2002, p. 53-60.

MOTTA-ROTH, D. Gêneros discursivos no ensino de língua para fins acadêmicos. In: FORTKAMP, M. B. M.; TOMITCH, L. M. B. (org.). Aspectos da linguística aplicada. Florianópolis: Insular, 2000.

SCHNEUWLY, B.; DOLZ, J. Os gêneros escolares - das práticas de linguagem aos objetos de ensino. In: SCHNEUWLY, B.; DOLZ, J. Gêneros orais e escritos na escola. Campinas: Mercado de Letras, 2004, p. 71-91. 
SILVA, S. R. da. Gênero textual e tipologia textual: colocações sob dois enfoques teóricos. Soletras. Ano X, No 20, jul./dez.2010. São Gonçalo: UERJ, 2010, p. 64-75.

SILVA, S. R. da; LIMA, V. C. O uso e as relações de sentido de conectivos nos diferentes tipos de texto. Trabalho Final da Disciplina "Tipos e Gêneros Textuais". Universidade Federal de Uberlândia MG: Instituto de Letras e Linguística - Mestrado em Linguística, 1999, (mimeo).

SWALES, J. Research into the structure on introductions to journal articles and its application to the teaching of academic writing. In: ELT documents 117 - commom ground: shared interest in ESP and communication studies, 77-86, 1984. 